\begin{abstract}
УДК $631.527 .8+631.524 .84$
АНАЛИЗ ВЛИЯНИЯ КОМБИНАЦИИ 7DS-7DL-7Ae\#1L + 1BL-1RS ТРАНСЛОКАЦИЙ НА ПРОДУКТИВНОСТЬ И КАЧЕСТВО ЗЕРНА ЯРОВОЙ МЯГКОЙ ПШЕНИЦЫ

\author{
Сибикеев С.Н., Дружин А.Е., Андреева Л.В.
}

ФГБНУ «Научно-исследовательский институт сельского хозяйства Юго-Востока», Саратов, e-mail: sibikeev_sergey@mail.ru

Чужеродные транслокации 1BL-1RS и 7DS-7DL-7Ae\#1L от ржи посевной и пырея удлинённого внесли значительный вклад в производство мягкой пшеницы. В настоящее время комбинация этих транслокаций высокоэффективна против листовой и стеблевой ржавчин. Однако их совместное влияние на хозяйственнополезные показатели почти не изучалось. В представленном исследовании агрономическая ценность комбинации 7DS-7DL-7Ae\#1L + 1BL-1RS - транслокаций изучалась на почти изогенных линиях яровой мягкой пшеницы сорта Л503 и линии Л2032 с 7DS-7DL-7Ae\#1L транслокациями. Источники 1BL-1RS- транслокации - линии ThatcherLr26, Curinda87, Seri82. Изучение проводилось с 2013 по 2017 гг., в вегетационные сезоны с благоприятными температурными и водными режимами. Экспериментальный материал высевался в 7 м $^{2}$ делянки рендомизировано в 4-кратной повторности. В исследованиях определяли продуктивность и качество зерна, которое оценивали по содержанию сырой клейковины, показателям прибора ИДК-1, а физические свойства теста устанавливали на альвеографе Шопена. Полученные данные подвергли дисперсионному анализу. Сравнение влияния 7DL-7Ae\#1L + 1BL-1RS- транслокаций на продуктивность зерна за два периода с 2005 по 2011 г. (засухи различной степени) и с 2013 по 2017 г. (благоприятные годы с эпифитотиями листовой и стеблевой ржавчины) показало разнонаправленность эффектов комбинации транслокаций. В засушливый период выявлено положительное влияние, а в благоприятный - негативное или нейтральное. В целом нет однозначно положительного или отрицательного влияния 7DS-7DL-7Ae\#1L + 1BL-1RS транслокаций на урожайность зерна вне зависимости от генотип-средовых взаимодействий. Более стабильно проявление влияния 7DL-7Ae\#1L + 1BL-1RS- транслокаций на показатели качества муки и хлеба. Обнаружено сходство эффектов (нейтральное) на показатели клейковины, упругость теста, отношение упругости теста к растяжимости. По силе муки выявлено снижение или нейтральное влияние и лишь объём хлебцев в засушливых условиях уменьшался, а в благоприятных увеличивался.
\end{abstract}

Ключевые слова: мягкая пшеница, 7DL-7Ae\#1L + 1BL-1RS- транслокации, почти изогенные линии, влияние на продуктивность и качество зерна, разнонаправленность эффектов

\title{
INFLUENCE ANALYSIS OF COMBINATION 7DS-7DL-7Ae\#1L + 1BL-1RS TRANSLOCATIONS ON SPRING WHEAT YIELD AND GRAIN QUALITY
}

\author{
Sibikeev S.N., Druzhin A.E., Andreeva L.V. \\ Agricultural Research Institute for South-East Regions, Saratov, e-mail: sibikeev_sergey@mail.ru
}

\begin{abstract}
The 1BL-1RS and 7DS-7DL-7Ae\#11 alien translocations from rye and elongated wheatgrass made a significant contribution to the bread wheat production. Currently, the combination of these translocations is highly effective against leaf and stem rust. However, their combined impact on agronomic useful traits was almost not studied. In this study, the agronomic value of the combination 7DS-7DL-7Ae\#1L + 1BL-1RS - translocation was studied on the nearly isogenic lines of spring bread wheat cultivar L503 and line L2032 with 7DS-7DL-7Ae\#1L translocations. The sources of 1BL-1RS - translocation were lines ThatcherLr26, Curinda87, Seri82. The study was conducted within the period 2013-2017. These vegetation seasons were favorable for temperature and water regimes. The experimental material was randomized sown in $7 \mathrm{~m}^{2}$ plots in 4-fold repetition. The productivity and quality of grain were determined in the research. The grain was detected by the content of crude gluten, indicators of the IDK-1. The physical properties of the dough were evaluated on the Chopin alveograph. The obtained data were subjected to ANOVA analysis. The comparison of the influence 7DL-7Ae\#1L + 1BL-1RS - translocation on the grain productivity within the two periods 2005-2011 (droughts of different degrees) and 2013-2017 (favorable years with epidemics of leaf and stem rust) have shown the divergence of the combination translocations effects. In the droughts period, the positive influence was revealed, and in the favorable - negative or neutral. In general, there is no unambiguously positive or negative influence of 7DS-7DL-7Ae\#1L + 1BL-1RS translocations on grain yield regardless of genotype-environmental interactions. The more stable appearance of the influence of 7DL-7Ae\#1L $+1 B L-1 R S$ translocations on the quality of flour and bread was detected. The similarity of the effects (neutral) on the gluten traits, the elasticity of the dough, and the ratio of the elasticity of the dough to the extensibility were determined. The strength of the flour showed a reduction or neutral influence, and only the volume of breads in drought conditions were decreased, but in the favorable increased.
\end{abstract}

Keywords: bread wheat, 7DL-7Ae\#1L + 1BL-1RS translocations, almost isogenic lines, influence on productivity and quality of grains, multidirectional effects

Виды Agropyrum elongatum $(2 \mathrm{n}=70)$ (Host) Beauv. и Secale cereale L. давно привлекают селекционеров мягкой пшеницы наличием ряда ценных генов, контролирующих зимостойкость, высокую морозоустой- чивость, устойчивость к целому ряду заболеваний и насекомых. В Каталоге генных символов за 2013 г. от пырея удлинённого зарегистрировано 8 генов, ответственных за устойчивость к различным заболевани- 
ям и вредным насекомым, а от ржи посевной - 20 [1]. Из этих 20 генов устойчивости к биострессорам наибольшее значение оказывают гены в транслокациях 1BL-1RS, coдержащей гены резистентности к листовой, стеблевой, желтой ржавчинам и мучнистой poce - Lr26, Sr31, $\operatorname{Yr} 9, \operatorname{Pm} 8$ и 1AL-1R\#2S, содержащей гены устойчивости к злаковой тле и мучнистой росе - Gb2, Pm17. Транслокация 1BL-1RS в настоящее время включена в родословные многих сортов мягкой пшеницы и получила широкое распространение в Центральной и Южной Америке, Западной Европе, Юго-Восточной Азии, Ближнем Востоке и Северной Африке и её присутствие в 1990-х гг. достигало $60 \%$. Рядом исследований было выявлено, что она способствует повышению продуктивности, устойчивости к засухе, формированию более крупного зерна и более эффективному использованию влаги корнями и росту надземной биомассы [2]. Однако эффективность генов устойчивости к возбудителям листовой и жёлтой ржавчинам и мучнистой росы была потеряна в 1970-е гг. [3]. Среди генов устойчивости от пырея удлинённого в России широкое распространение получили гены Lr19/Sr25 в 7DS7DL-7Ae\#1L - транслокации. Причём набор сортов с этими генами в основном сосредоточены в европейской части России. Влияние на агрономические признаки 7DS7DL-7Ae\#1L - транслокации оценивается как положительное $[4,5]$. Отмечалось, что увеличение продуктивности зерна этой транслокацией определяется лучшим использованием ассимилятов репродуктивными органами [6]. Как и в случае с $L r 26$, ген $\operatorname{Lr} 19$ был преодолён патогеном [5]. В целом вклад обеих транслокаций в мировую практику сельского хозяйства оценивается как высокий. Как показали исследования, несмотря на преодолённость генов Lr26 и $\operatorname{Lr19}$, их комбинация высокоэффективна как в европейской части России, так и в западной Сибири [3]. Однако комбинация 7DS-7DL-7Ae\#1L + 1BL-1RS транслокаций в генетической среде яровой мягкой пшеницы мало распространена, почти не изучалась и их совместные эффекты не ясны, что побудило нас создать для этих целей набор соответствующих изолиний на генотипе широко распространенного сорта Л503 и линии Л 2032.

Цель исследования: по результатам многолетних исследований почти изогенных линий яровой мягкой пшеницы определить влияние комбинации транслокаций 7DS-
7DL-7Ae\#1L + 1BL-1RS на продуктивность зерна и показатели качества муки и хлеба.

\section{Материалы и методы исследования}

Используемый материал включал следующие генотипы:

генотипы-реципиенты: сорт яровой мягкой пшеницы Л503 и линия Л2032=Л504/ Краснокутка 10//Л504 - доноры 7DS-7DL7Ae\#1L транслокации;

почти изогенные линии яровой мягкой пшеницы: Л503*6//Tc Lr26, где Tс Lr26- почти изогенная линия сорта Thatcher с геном Lr26, то есть с транслокацией 1BL-1RS; Л2032*6//Curinda87, где линия Curinda87 выведена в СИММИТ (Мексика) и является носителем 1BL-1RS - транслокации; Л2032*5//Seri82, где линия Seri82 выведена в СИММИТ (Мексика) и является носителем 1BL-1RS - транслокации; Л2032*6// Tc Lr26; пара почти изогенных сибсов Л359R и Л359S, где сибс R с транслокацией 7DS7DL-7Ae\#1L, а сибс $\mathrm{S}$ - нет.

Исследования включали оценку продуктивности зерна, физических свойства теста и хлебопекарных показателей. Исследования проводились в 2013-2017 гг., из которых наиболее благоприятными были 2014 и 2017 гг, 2013 и 2015 гг. были средними по увлажнению, а 2016 г. выделялся повышенным количеством осадков и сильной эпифитотией стеблевой ржавчины и жёлтой пятнистости. Эпифитотии листовой ржавчины отмечались в 2014 и в 2017 гг. Кроме того, в начале вегетации в 2017 г. (до стадии трубкования) отмечалась эпифитотия септориоза листьев. Экспериментальный материал рендомизированно высевался в 7 м² делянки в 4-кратной повторности. Норма

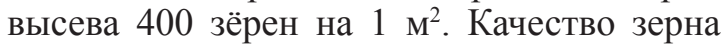
и теста оценивали по содержанию сырой клейковины и показателям прибора ИДК-1 и альвеографа Шопена с выпечкой опытных образцов хлебцев. Полученные данные подвергли соответствующему статистическому анализу с использованием программ «Agros-2.10». Сравнения были проведены в пределах почти изогенных пар или набора линий с соответствующим сортом или линией-реципиентом.

\section{Результаты исследования и их обсуждение}

Результаты изучения продуктивности зерна показали, что в среднем за период с 2013 по 2017 гг. отмечено понижение урожайности у линий Л2032*6//Curinda87, Л2032*6//TcLr26, Л2032*5//Seri82 по срав- 
нению с Л2032. Причём у двух последних линий это понижение урожайности зерна было статистически значимым. Урожайность зерна у Л2032*6//Curinda87 в течение пяти лет (2013-2017 гг.) была постоянно ниже, чем у Л2032, причём четыре года незначимо и лишь один год (2017 г.) различия были достоверными. В среднем снижение составило 215 кг/га или 6\%. У Л2032*6// TcLr26 значимое снижение урожайности было три года и в целом составило 418 кг/га или $12 \%$. У Л2032*5//Seri82 значимое снижение урожайности было четыре года и в целом составило $11 \%$. У Л503 (Lr19+Lr26) за этот же период по сравнению с сортом Л503 (Lr19) значимых различий по продуктивности зерна не было установлено (снижение составило лишь $1 \%$ ). В течение пяти лет (2013-2017 гг.) Л503 (Lr19+Lr26) значимо снизил продуктивность зерна в 2014 г. и значимо превысил в 2016 г., в остальные годы достоверных различий по урожайности зерна не было (таблица). но. В более ранних исследованиях [7], при использовании пары Л503 и Л503*6//Tc Lr26 за период 2005-2011 гг. было выявлено достоверное увеличение продуктивности зерна у линии с комбинацией 7DS7DL-7Ae\#1L + 1BL-1RS - транслокаций. Увеличение урожайности достигало $19 \%$. Причиной расхождения выводов о влиянии комбинации 7DS-7DL-7Ae\#1L + 1BL1RS- транслокаций является различное сочетание количества лет с засушливыми условиями и благоприятных лет. Так в период с 2005 по 2011 гг. наблюдалось четыре среднезасушливых и три острозасушливых года, благоприятных по увлажнению лет не было. В период с 2013 по 2017 гг. наблюдалось два средних и три благоприятных по увлажнению года, засушливых лет не было. Таким образом, есть основания утверждать что положительный эффект взаимодействия 7DS-7DL-7Ae\#1L + 1BL-1RS на продуктивность зерна проявляется на фоне засушливых лет. Данный вывод со-

Продуктивность зерна и показатели качества у почти изогенных линий яровой мягкой пшеницы с транслокацией 7DS-7DL-7Ae\#1L и комбинацией транслокаций 7DS-7DL-7Ae\#1L + 1BL-1RS, среднее за 2013-2017 гг.

\begin{tabular}{|c|c|c|c|c|c|c|c|}
\hline \multirow[t]{2}{*}{ Сорта, линии } & \multirow{2}{*}{$\begin{array}{c}\text { Продуктивность } \\
\text { зерна, кг/га }\end{array}$} & \multicolumn{6}{|c|}{ Показатели качества муки и хлеба } \\
\hline & & клейковина* & $\mathrm{P}^{* *}, \mathrm{MM}$ & $\mathrm{P} / \mathrm{L}^{* *}$ & $\mathrm{~W}^{* *}$, e.a & $\mathrm{V}^{* *}, \mathrm{~cm}^{3}$ & пористость, балл \\
\hline Л2032 & $3514,2 \mathrm{~b}^{* * *}$ & $33 / 71 \mathrm{~ns} n s$ & $132 \mathrm{~ns}$ & $2,3 \mathrm{~ns}$ & $300 \mathrm{a}$ & $812 \mathrm{a}$ & $4,9 \mathrm{~ns}$ \\
\hline Л2032*6//Curinda87 & $3297,6 \mathrm{ab}$ & $35 / 78 \mathrm{~ns} n s$ & $111 \mathrm{~ns}$ & $2,0 \mathrm{~ns}$ & $252 b$ & $869 \mathrm{c}$ & $5,0 \mathrm{~ns}$ \\
\hline Л2032*6// Tc Lr26 & $3096,6 \mathrm{a}$ & $34 / 69$ ns ns & $111 \mathrm{~ns}$ & $2,1 \mathrm{~ns}$ & $252 b$ & $866 \mathrm{c}$ & $5,0 \mathrm{~ns}$ \\
\hline Л2032*5//Seri82 & $3198 \mathrm{a}$ & $32 / 71 \mathrm{~ns} n s$ & 110ns & $2,3 \mathrm{~ns}$ & $208 \mathrm{c}$ & $848 b$ & $4,9 \mathrm{~ns}$ \\
\hline Л503 & $3096,8 \mathrm{~ns}$ & $33 / 80$ ns ns & 100ns & $2,1 \mathrm{~ns}$ & $187 \mathrm{~ns}$ & $830 \mathrm{a}$ & $4,8 \mathrm{~ns}$ \\
\hline Л503*6//Tc Lr26 & $3071,8 \mathrm{~ns}$ & 33/80 ns ns & $102 \mathrm{~ns}$ & $2,0 \mathrm{~ns}$ & $204 n s$ & $860 \mathrm{~b}$ & $4,9 \mathrm{~ns}$ \\
\hline Л359S $(\operatorname{lr} 19)$ & $2844,8 \mathrm{~ns}$ & $32 / 71$ a ns & 100ns & $2,0 \mathrm{~ns}$ & $205 n s$ & $830 \mathrm{a}$ & $4,8 \mathrm{~ns}$ \\
\hline Л359R(Lr19) & $2863,8 \mathrm{~ns}$ & $34 / 71 \mathrm{~b} \mathrm{~ns}$ & $97 \mathrm{~ns}$ & $2,0 \mathrm{~ns}$ & $194 n s$ & $770 b$ & $4,5 \mathrm{~ns}$ \\
\hline
\end{tabular}

Пр и м еч ан и е . * - в колонке первым указано количество клейковины/затем показатель прибора ИДК-1; ${ }^{* *} \mathrm{P}$ - упругость теста, $\mathrm{P} / \mathrm{L}$ - отношение упругости теста к растяжимости, $\mathrm{W}$ - сила муки, $\mathrm{V}$ - объём хлеба; ${ }^{* * *}$ - числа в колонках, сопровождаемые различными буквами, значимо различаются на уровне $\mathrm{P}_{005}$.

Таким образом, чётко проявился эффект источника 1BL-1RS - транслокации и сорта, линии-реципиента. Несмотря на высокое и почти одинаковое количество беккроссов (5-6) можно утверждать, что для оптимального приближения к генотипу Л2032, при использовании линий ThatcherLr26 и Seri82 необходимо ещё большее количество возвратных скрещиваний. Тем не менее тренд снижения продуктивности зерна проявился у всех линий, но у Л $2032 * 6 / /$ Curinda87 u Л503*6//Tc Lr26 несуществен- гласуется с тем, что 1BL-1RS способствуют нарастанию большей массы корней и более эффективному использованию влаги корнями и росту надземной биомассы [2]. Для выявления отдельного влияния 7DS-7DL7Ae\#1L - транслокации на урожайность зерна нами использовалась почти изогенная пара сибсов Л359S и Л359R с отсутствием и наличием транслокации соответственно. Анализ продуктивности зерна показал, что за период с 2013 по 2017 гг. вклад 7DS-7DL7Ae\#1L - транслокации оценивается как 
нейтральный (таблица). В связи с тем, что у нас отсутствовала почти изогенная пара по 1BL-1RS, мы можем только предполагать, что установленное снижение продуктивности в 2013-2017 гг. у линий с 7DS-7DL7Ae\#1L + 1BL-1RS связано с эффектами 1BL-1RS-транслокации. Наши данные не согласуются с результатами Singh с соавт., выполненными на почти изогенных линиях сорта Seri 82 [4]. По данным этих авторов комбинация 7DL-7Ae\#1L + 1BL-1RSтранслокаций увеличивает продуктивность зерна в условиях недостатка влаги на 8,2\%, а в условиях достаточного увлажнения до $16 \%$. Результаты наших исследований приводят к противоположным выводам, и это несмотря на то, что в одной из линий источник 1BL-1RS-транслокации также был сорт Seri 82. По-видимому, сказывается принципиально разные условия выращивания (сроки вегетации яровой пшеницы в Мексике достигают 210-240 дней, в Поволжье 105-115 дней, и разный температурный режим). Кроме того, без сомнения, проявляется эффект генотипов сортов-реципиентов. Однако вопрос, почему, несмотря на высокоэффективную устойчивость к листовой и стеблевой ржавчине и в условиях эпифитотий этих патогенов линии на основе Л2032 не имели преимуществ по урожайности зерна, остаётся невыясненным. Более того, почти изогенная линия на основе Л503 значимо превысила сорт-реципиент, только в условиях 2016 г. (сильная эпифитотия стеблевой ржавчины), но отмечалось снижение продуктивности зерна в условиях эпифитотий листовой ржавчины в 2014 и 2017 гг. Причины этого снижения не ясны.

Таким образом, анализируя ранее полученные и последние результаты по влиянию комбинации 7DL-7Ae\#1L + 1BL-1RS- транслокаций на продуктивность зерна, можно говорить о различном её проявлении в зависимости от конкретно складывающихся условий вегетации, то есть норме реакции генотипа. Следовательно, нет однозначно положительного или отрицательного влияния комбинации вышеуказанных транслокаций на урожайность зерна вне зависимости от генотип-средовых взаимодействий.

Немаловажное значение в сельскохозяйственном производстве играет качество конечной продукции растениеводства. Широко известно отрицательное влияние $1 \mathrm{BL}-1 \mathrm{RS}-\mathrm{p}$ анслокации на хлебопекарные свойства [2] и положительное у 7DL-7Ae\#1L-транслокации [5], (кроме цвета мякиша). Ранее было выявлено, что комбинация 7DL-7Ae\#1L + 1BL-1RS- транслокаций не влияет на содержание клейковины и её качество, упругость теста, отношение упругости теста к растяжимости, но снижает силу муки. По хлебопекарным свойствам было выявлено незначимое снижение объёма хлебцев и по пористости не было различий [7]. Данные по оценке показателей качества муки и хлеба подтвердили ранее сделанные выводы, кроме объёма хлебцев (таблица). За период 2013-2017 гг. все почти изогенные линии c 7DL-7Ae\#1L + 1BL-1RS-транслокациями значимо повысили объём хлебцев и были незначимо лучше по пористости. Следует отметить незначимое снижение упругости теста и достоверное уменьшение силы муки у всего набора линий на основе Л2032. В то время как у Л503*6//Tc Lr26 упругость теста и сила муки не снижалась, а была даже несколько выше, но в пределах наименьшей существенной разницы. Данный факт подтверждает необходимость изучения эффектов чужеродных транслокаций на нескольких генотипах-реципиентах для правильных выводов. Изучение отдельного вклада 7DL-7Ae\#1L-транслокации у пары сибсов Л359S и Л359R показал, что пырейная транслокация значимо увеличивает количество клейковины, не изменяя её качество и не влияет на упругость теста, отношение упругости к растяжению теста и силу муки. Однако значимо понижает объём хлебцев при одинаковой пористости. Таким образом, есть основания утверждать, что уменьшение силы муки, равное количество клейковины и увеличение объёма хлебцев у комбинации 7DL-7Ae\#1L + 1BL1RS-транслокаций определяется вкладом 1BL-1RS-транслокации в эффект на хлебопекарные показатели.

\section{Выводы}

Анализ влияния 7DL-7Ae\#1L + 1BL$1 \mathrm{RS}-$ рранслокаций на продуктивность зерна у почти изогенных линий яровой мягкой пшеницы за два периода с 2005 по 2011 гг. (засухи различной степени) и с 2013 по 2017 гг. (благоприятные годы с эпифитотиями листовой и стеблевой ржавчины) показал разнонаправленность эффектов комбинации транслокаций. В засушливый период выявлено положительное влияние, а в благоприятный - негативное или нейтральное. В целом нет однозначно положительного или отрицательного влияния комбинации вышеуказанных транслокаций на урожайность зерна вне зависимости от генотипсредовых взаимодействий. 
Более стабильно проявление влияния 7DL-7Ae\#1L + 1BL-1RS-транслокаций на показатели качества муки и хлеба. Обнаружено сходство эффектов (нейтральное) на показатели клейковины, упругость теста, отношение упругости теста к растяжимости. По силе муки выявлено снижение или нейтральное влияние, и только по объёму хлебцев установлено расхождение эффектов комбинаций. В засушливых условиях объём хлебцев уменьшался, а в благоприятных увеличивался.

\section{Список литературы}

1. Catalogue of Gene Symbols for Wheat/ R.A. McIntosh [et al.] // Proceedings of the 12th International Wheat Genetics Symposium, 8-13 September 2013, Yokohama, Japan.

2. Harnessing diversity in wheat to enhance grain yield, climate resilience, disease and insect pest resistance and nutrition through conventional and modern breeding approaches / S Mondel [et al.] // Frontiers in plant science. 2016. No. 6.:991. DOI: $10.3389 /$ fpls.2016.00991.

3. Генетическая структура российских и казахстанских популяций возбудителя бурой ржавчины Puccinia triticina Erikss. по вирулентности и SSR маркёрам/ Е.И. Гультяева [и др.] // Сельскохозяйственная биология. -2018 . - Т. 53 , № 1. - C. 85-95. DOI: 10.15389/agrobiology.2018.1.85rus.

4. Singh R.P., Huerta-Espino J., Rajaram S., Crossa J. Agronomic effects from chromosome translocations 7DL.7AG and 1BL.1RS in spring wheat. Crop Science, 1998, Vol.38, P. 27-33. DOI: $10.2135 /$ cropsci1998.0011183X003800010005x.

5. Sibikeev S.N., Druzhin A.E. Prebreeding research of near-isogenic lines of spring bread wheat with a combination of translocations from Agropyron elongatum (Host.) P.B and Aegilops ventricosa Tausch. Russian Journal of Genetics: Applied research, 2016, Vol. 3, P. 338-343. DOI: 10.1134 S2079059716030126.

6. Miralles D.J., Resnicoff E., Carrtero R. «Yield improvement associated with Lr19 translocation in wheat: which plant attributes are modified?» in Scale and Complexity in Plant Systems Research: Gene-Plant-Crop Relations, eds J.H.J. Spiertz,
P.C. Struik, and H.H. van Laar (Dordrecht: Springer) 2007, P. 169-176.

7. Sibikeev S.N., Druzhin A.E., Voronina S.A. The influence of a translocation with the Lr19+Lr26 combination on grain productivity and bread-making quality in spring bread wheat. Annual Wheat Newsletter. Kansas State University, USA, 2013, Vol. 58, P. 207.

\section{References}

1. Catalogue of Gene Symbols for Wheat/ R.A. McIntosh [et al.] // Proceedings of the 12th International Wheat Genetics Symposium, 8-13 September 2013, Yokohama, Japan.

2. Harnessing diversity in wheat to enhance grain yield, climate resilience, disease and insect pest resistance and nutrition through conventional and modern breeding approaches / S. Mondel [et al.] // Frontiers in plant science. 2016. No. 6.:991. DOI: 10.3389 /fpls.2016.00991.

3. Geneticheskaya struktura rossijskix i kazaxstanskix populyacij vozbuditelya buroj rzhavchiny` Puccinia triticina Erikss. po virulentnosti i SSR markyoram / E.I. Gul tyaeva [i dr.] // Sel’skoxozyajstvennaya biologiya. - 2018. - T. 53, № 1. P. 85-95. DOI: 10.15389/agrobiology.2018.1.85rus.

4. Singh R.P., Huerta-Espino J., Rajaram S., Crossa J. Agronomic effects from chromosome translocations $7 \mathrm{DL} .7 \mathrm{AG}$ and 1BL.1RS in spring wheat. Crop Science, 1998, Vol. 38, P. 27-33. DOI: $10.2135 /$ cropsci1998.0011183X003800010005x.

5. Sibikeev S.N., Druzhin A.E. Prebreeding research of near-isogenic lines of spring bread wheat with a combination of translocations from Agropyron elongatum (Host.) P.B. and Aegilops ventricosa Tausch. Russian Journal of Genetics: Applied research, 2016, Vol. 3, P. 338-343. DOI: 10.1134/ S2079059716030126.

6. Miralles D.J., Resnicoff E., Carrtero R. «Yield improvement associated with Lr19 translocation in wheat: which plant attributes are modified?» in Scale and Complexity in Plant Systems Research: Gene-Plant-Crop Relations, eds J.H.J. Spiertz, P.C. Struik, and H.H. van Laar (Dordrecht: Springer) 2007, P. 169-176.

7. Sibikeev S.N., Druzhin A.E., Voronina S.A. The influence of a translocation with the Lr19+Lr26 combination on grain productivity and bread-making quality in spring bread wheat. Annual Wheat Newsletter. Kansas State University, USA, 2013, Vol. 58, P. 207. 